\title{
HARMONY RULES IN CHINESE BACKPACKER GROUPS
}

\section{ABSTRACT}

Despite recognition that Chinese backpackers travel in small, self-organised groups, studies have yet to examine how group dynamics affect the travel experience. Multi-sited ethnography and netnography were deployed to follow Chinese backpackers in Europe to explore their group dynamics. The findings reveal that Chinese backpackers sustain hierarchical group relations by applying cultural attributes of 'respect for authority' and 'keqi'. A conflict-free status is achieved by following the codes of 'guanxi' and 'conformity'. Harmony is practiced to either develop harmonious relationships or resolve potential discord. This study contributes to the literature on harmony by synthesising relevant cultural attributes to understand their applications in group dynamic. It furthermore contributes to the literature on backpacker tourism and self-organised travel group dynamics.

Keywords: harmony; group dynamics; Chinese outbound backpackers; discord; mobile ethnography; travel experience 


\section{INTRODUCTION}

Harmony as the fundamental concept in Confucianism has been widely discussed in the literature to understand behaviours, societies and relations with external environments (c.f. Kwek \& Lee, 2010, 2015; Qian, 2001; Yang, Ryan, \& Zhang, 2016). In studies of Chinese tourists, group harmony provides critical insights into their experience as it largely influences their group behaviours (Kwek \& Lee, 2010). Several theoretical frameworks of the notion of harmony have been proposed alongside a range of traditional Chinese values to investigate travel experiences in various contexts, such as outbound corporate tourists' behaviours (Kwek \& Lee, 2015) and tourism marketing (Mok \& DeFranco, 2000). Although these studies have identified the influence of group harmony in travel experiences, the role of group dynamics has been largely overlooked. Furthermore, while studies have connected group harmony to Chinese cultural attributes, scholars have not yet examined how these attributes interact with a variety of levels of harmony. Investigating various levels of harmony and their influence on group dynamics is an important aspect of understanding the role that group harmony plays in tourism experiences.

The study of group dynamics in tourism experiences is increasingly interlinked with the popularisation of self-organised travel, and Song, Wang and Sparks (2018) have called for studies on the interactions of the self-organised group. In the last few decades, tourism products and practices have diversified (Benur \& Bramwell, 2015), including many types of tourism that are independently organised and individualised. This has led to a gradual focus on individual experiences. Self-organised groups in China have grown in popularity (Song et al., 2018), as increasing numbers of individuals choose to take more control of who they travel with (Miao $\&$ Bao, 2007) than afforded by package tours. Compared with studies of package tour groups (Yu, Weiler, \& Ham, 2002), and at the other end of a spectrum, solo travellers (Adkins \& Grant, 2007), self-organised travelling groups have been largely overlooked in the literature. In addition, group dynamics are highly influenced by cultural values, which cannot be neglected when investigating a culturally homogeneous group, such as Chinese backpackers.

For decades, backpacker studies have principally looked at backpackers from the West to less developed countries (du Cros \& Jingya, 2013). However, continuing globalisation and a nascent emphasis on mobilities from emerging world regions have resulted in a shift in focus away from 
this previous Euro- or Anglo-centric viewpoint (Cohen \& Cohen, 2015). Recent studies of Chinese backpackers have focused on cognitive aspects, such as motivations (Chen, Bao \& Huang, 2014), personal development (Chen \& Huang, 2017), generalised self-efficacy and selfesteem (Chen, Huang \& Hu, 2018) and identities (Zhang, Morrison, Tucker, \& Wu, 2018; Zhang, Tucker, Morrison \& Wu, 2017). Given the group orientations of Chinese backpackers (Miao \& Bao, 2007), the significant role of group dynamics should not be neglected in understanding backpacker experiences. In addition, although with a few exceptions (see Ong \& du Cros, 2012; Prayag, Disegna, Cohen \& Yan, 2015; Wu \& Pearce, 2014), scholars mainly confine their studies of Chinese backpackers to the domestic context (see Chen et al., 2018; Chen \& Huang, 2017; Lim, 2009; Zhang et al., 2018; Zhang et al., 2017; Zhu, 2005, 2009). Research on Chinese backpackers in overseas destinations, especially in European countries, remains limited. Furthermore, there have been calls to develop a deeper understanding of Chinese outbound travellers through in-depth qualitative studies (Chen et al., 2014; Jin \& Wang, 2016).

With its growing popularity (ITB, 2018), the independent segment of Chinese outbound tourism has been identified by recent studies (Prayag et al., 2015). Chinese outbound backpackers, with characteristics of group orientation, tech-savviness and higher levels of risk avoidance (Luo, Huang, \& Brown, 2015), are chosen in this study as the context to explore the role of harmony in group dynamics. Travelling in an unfamiliar environment, individual Chinese backpackers tend to form travel groups in advance online to buffer cultural confusion (Miao \& Bao, 2007).

Previous studies have only emphasised the impromptu nature of Western backpackers forming groups on the road (Murphy, 2001; Sørensen, 2003). This unique group make-up of Chinese outbound backpackers, in which travellers develop from strangers to companions, not only contributes to the backpacker literature from a cross-cultural perspective, but also offers rich opportunities to explore the functions and outcomes of cultural attributes and different levels of harmony within Chinese backpacker groups. To address the gaps in knowledge of selforganised travellers' group dynamics, the cultural influence of group harmony and contribute to the understanding of Chinese outbound backpackers, this study addressed the research question: how can group harmony and its relationships with key traditional Chinese cultural attributes allow for new understandings of Chinese outbound backpackers' group dynamics? 


\section{LITERATURE REVIEW}

\subsection{Chinese backpackers}

In the past four decades, Western backpackers' motivations (Paris and Teye, 2010; Pearce and Foster; 2007), characteristics (Loker-Murphy and Pearce, 1995), and social activities (Sørensen, 2003) have been widely explored. Despite sharing similar travel motivations such as social interaction and self-actualisation (Chen et al., 2014), Chinese backpackers have several distinct characteristics from Western backpackers (Lim, 2009; Zhu, 2005). In addition to Western backpacking culture's large influence on Chinese backpackers' motivations, traditional Chinese values, such as appreciation for landscapes, social power hierarchy and high uncertainty avoidance, play a significant role in shaping Chinese backpackers' characteristics. Demographically, the age range of Chinese backpackers is generally wider than their Western counterparts (Lim, 2009), which reflects the high pressure of social responsibility in the Chinese younger generation. The 'gap year' - understood as taking a year off to travel, volunteer or work abroad - is considered a rebellion against orthodoxy, and is not acceptable in either the Chinese educational system or the Chinese moral code (Zhang et al., 2018). In addition, the 'one child policy' has resulted in 'excessive attention' on only children from their parents (Fong, 2004), which certainly hinders the development of backpacker tourism among Chinese teenagers.

The role of the Internet has also been highlighted as affecting all phases of the Chinese backpacker experience (pre, during and after) (Long, 2011), and Chinese backpackers are highly active socialisers in travel forums (Luo et al., 2015; Ong \& du Cros, 2012). Sharing and gaining backpacking experience and sources on key online travel forums (e.g. Qyer.com; Mafengwo.com) is the main channel for Chinese backpackers to collect information (Xiang, 2013). Moreover, it has become popular among Chinese backpackers to look for travel companions online (Miao \& Bao, 2007; Zhang et al., 2018). Qyer.com, a popular website among Chinese backpackers to search for travel companions, lists 110,394 Chinese backpackers who are seeking to form travel groups, from the platform's 50 million users, with 6,000 of them departing within a month (accessed $1^{\text {st }}$ June 2018). This preference for group travel can be attributed to a higher level of uncertainty avoidance in Chinese culture (Money \& Crotts, 2003). 
Chinese backpackers also have a more flexible travel budget, shorter lengths of stay, and stronger dependence on supplemental facilities, such as higher requirements of accommodation and transport (Zhang et al., 2018; Zhu, 2009). These practices can be attributed to lower endurance and maturity in backpacking (Zhu, 2009), a greater level of risk sensitiveness (Wong \& Lau, 2001), and restricted holiday allowances in China (Luo et al., 2015).

Arguably, there are strong differences between domestic and outbound Chinese backpackers. We argue that Chinese backpackers can be divided into two main categories, influenced by various streams of culture. The first category is domestic Chinese backpackers who are influenced by landscape appreciation in traditional Chinese culture. They have been shown to prefer outdoor activities, reflecting similarities with adventure travellers (Chen et al., 2014; Zhang et al., 2018). Zhu (2005, 2009) argues that domestic Chinese backpackers most resemble 'explorers', as characterised by Cohen (1972)'s typology, as opposed to the category of 'drifter' from which Western backpackers originated (Zhu, 2009). Currently, this category of Chinese backpackers tend to travel domestically. The second category, Chinese outbound backpackers, reflects 'flashpackers' (Paris, 2012), with the characteristics of tech-savviness and affluence. This category tends to avoid cultural risk, and can be understood as flashpackers with distinct characteristics such as group orientations and social hierarchy.

With the increasingly blurred boundaries between backpackers and other type of tourists (Zhang et al., 2017), and the growing number of independent outbound travellers from China identifying themselves as backpackers (Prayag et al., 2015), in this study, we build upon the arguments of Nash, Thyne, and Davies (2006) and Prayag et al. (2015), and further confirm synonymy between Chinese outbound backpackers and Chinese independent travellers. Thus, the monolithic view of Chinese backpackers as adventure travellers requires revisiting in these complexities.

\subsection{Group harmony and four Chinese cultural attributes}

The notion of group harmony has been explored externally and internally in terms of tourist behaviour. Internally, studies of group harmony largely focus on various levels of harmony in interpersonal relationships. Huang (1999) suggests two major types of harmony: 'genuine harmony' refers to sincere and holistic relationships, whilst 'surface harmony' is widely used to cover discord by appearing conflict-free on the surface. Correspondingly, Leung, Koch, and Lu (2002) propose a dualistic model of harmony by applying a value-instrumental perspective 
to classify harmony as 'harmony enhancement' and 'disintegration avoidance', which are similar to Huang (1999)'s typology. Huang (1999) further argues that genuine harmony is difficult to achieve, and Chang (2001) indicates that most Chinese interpersonal interactions, particularly with acquaintances, are social performances at a relatively superficial level. Compared with direct confrontations, which might lead to discord, Chinese people still prefer surface harmony as a tool to sustain relationships, although it is not optimal (Leung \& Wu, 1998). Therefore, the surface harmony that covers confrontations, but retains disagreements, is likely to lead to discordant travel group dynamics. We can, therefore, suggest a spectrum of group harmony with one end of discordant group dynamics and the other end of genuine harmonious group dynamics. Surface harmony functions actively on the end of discord to cover conflicts and disagreements.

Externally, several conceptual frameworks (see Kwek \& Lee, 2010; Mok \& DeFranco, 2000) have been proposed to link the notion of harmony with various cultural attributes in order to investigate Chinese tourists' behaviours. These studies, although emphasising the significant role of harmony as well as its connections with other cultural attributes in shaping Chinese travellers' experiences, drew little attention to group dynamics, and how the different levels of group harmony affect travel experiences. It is important to consider how related Chinese cultural attributes may play roles in between genuine harmony and discord to facilitate group dynamics. Based on the group orientation of Chinese backpackers (Luo et al., 2015; Miao \& Bao, 2007), we synthesise here four Chinese cultural attributes that facilitate different stages of group dynamics, and result in various levels of group harmony: conformity, respect for authority, guanxi and keqi.

The cultural value of conformity suggests the suppression of individual goals and interests, as well as forbearance in the group to pursue collectivistic harmony (Baron \& Kerr, 2003; Leung et al., 2002). Guided by the principle of harmony, compromise, as well as conflict and confrontation avoidance, conformity is a common practice in Chinese societies and organisations (Moise, 1995). Hsu and Huang (2016) suggest that to build a sense of harmony, Chinese tourists consider themselves as team players, and the value of conformity to some extent influences their preferences and group decisions in tourist activities.

In addition to understanding Chinese groups in terms of the cultural attribute of conformity, respect for authority, guanxi, and keqi provide insight into how interpersonal relationships are 
formed and practiced based on interpretations of harmony. Firstly, social relations in Chinese groups are hierarchical. The strong social hierarchy results from high power distance in China (Hofstede, 1980), and leads to strong respect for authority in Chinese daily practices (Yau, 1988). Respect for authority has been largely discussed as a key cultural value influencing group interactions (Kwek \& Lee, 2010, 2015; Mok \& DeFranco, 2000). In the context of Chinese backpackers, respect for authority is reflected by the emergence and acceptance of a 'head donkey' (the leader in a Chinese backpacker group) by other 'donkey friends' in the same group. The head donkey in small groups of Chinese backpackers holds the power and has responsibility for the group (Lim, 2009). The wordplay of 'donkey friend' and 'head donkey' with homophones is an example of a 'distinct cultural entity' of Chinese backpackers (Lim, 2009). In Mandarin, 'donkey' is homophonic with 'travel'. In addition, the stereotype of donkeys always carrying large luggage coincidently suits the image of backpackers.

Based on this power distance in Chinese social groups, Chinese largely practice guanxi and keqi in their interpersonal relationships. Guanxi, understood as the Chinese system of social networks and influential relationships, has been broadly discussed in studies of Chinese interpersonal relationships in business, society and in organisations (Wong \& Tam, 2000). In addition to its literal meaning of 'relationship', Peng (1997) and Chen and Chen (2004) suggest that guanxi is defined as mutual obligations, commitments and understandings between two parties. In tourism research, several studies argue that guanxi provides a guideline and acts as an influential driver for Chinese tourists within group dynamics in the context of package tours (Kwek \& Lee, 2010; Pearce, Wu, \& Osmond, 2013).

$K e q i$, as an important Chinese cultural attribute to build up guanxi or to keep a courteous distance with acquaintances, is largely practiced in interpersonal relations. Keqi can be understood as 'well-mannered politeness' (Yao, 1983), and requires prudence and caution in communication. By practicing keqi, acquaintances show their attempts to develop a harmonious relationship towards a genuine level (Chen, 2013; Feng \& Chen, 2004). For group travel, the practice of keqi is crucial to building up relationships to achieve guanxi and a harmonious communication climate (Xiao, 2004).

While conformity suggests a practical interpretation of group harmony by achieving one ultimate goal within the group, respect for authority, guanxi, and keqi are adopted to deal with various interpersonal relationships to meet this goal. These four cultural attributes, therefore, 
provide multifaceted theoretical insights to investigate various levels of group harmony, ranging from genuine harmony to discord, with the latter veiled by surface harmony.

\subsection{Group dynamics}

Travel group dynamics play a critical role in shaping individuals' travel experiences. However, in comparison to widely studied host and guest interactions (McIntosh \& Zahra, 2007; Prebensen \& Foss, 2011), self-organised travel group dynamics have been largely overlooked. Travel group dynamics have been explored in the context of package tours, such as within cruise (Yarnal \& Kerstetter, 2005), coach (Quiroga, 1990; Tucker, 2005), and incentive holidays (Kwek \& Lee, 2010). Quiroga (1990) summarises the characteristics that influence the formation and development of social groups. They include the setting, physical proximity, amount of shared time, temporality, heterogeneity, companions' shared circumstances, and the awareness of sharing travel experiences. While Quiroga's work focuses on organised tours' group dynamics, these characteristics also apply to self-organised travel groups. Based on these characteristics that determine travel group development, a conclusion can be drawn that group travel experience is highly related to dynamics between travel companions.

Thornton, Williams and Shaw (1997) argue that a travel group's standard, expectations and goals largely determine an individual's travel experience. Acknowledging that group travel facilitates positive travel experiences by avoiding loneliness and boredom (Shaffer, 2004; Yarnal \& Kerstetter, 2005), it is worth noting that, to meet the group goal, individuals' preferences may be suppressed (Gilbert, 1992; Tuomela, 1995), which can potentially lead to negative travel experiences. To meet group goals and expectations, Crompton (1981) suggests instead of enacting individuals' desires on others, negotiations and compromises are common practices for group tourist behaviours based on the interactive group nature. In addition, Yarnal and Kerstetter (2005) argue that members of the group are linked under obligation, and represent the group. This social tie encourages a focus on the collective group rather than the individual. Individuals in the group, therefore, require considerations of others' preferences and opinions, which has significant impacts on overall travel experiences if there is a significant difference between individuals in the group.

In contrast to young Chinese who enjoy travelling in friendship groups (Song et al., 2018), 
Chinese backpackers commonly look for travel companions online to overcome the shortcomings of travelling with friends, relatives and colleagues who do not share the same interest in backpacking (Miao \& Bao, 2007). As a quasi-replacement for the tour leader in package groups, Luo et al. (2015) argue that the head donkey, who makes detailed decisions throughout the trip on behalf of the Chinese backpacker group, is the key to the success of the trip. Although motivations and the role of a group leader have been discussed in the group travel literature (Luo et al., 2015; Zhang \& Watts, 2008), group dynamic as an essential factor in travel experiences is still under-researched given the increasing popularity of self-organised travel. Studying the travel group dynamics of Chinese backpackers can thus contribute significantly to understanding their travel experiences.

\section{METHODS}

This research is underpinned by the interpretivist paradigm and responds to calls for a shift in tourism studies away from Eurocentrism through the study of emerging regions (Cohen \& Cohen, 2015). It adopts mobile ethnography as its research strategy, by combining multi-sited ethnography (Falzon, 2016; Marcus, 1995) with netnography (Kozinets, 2015) in order to gain insights into Chinese backpackers' group dynamics. A mobile ethnographic technique of 'follow the people' (Marcus, 1995) was employed to immerse the lead author in Chinese backpacker groups. To engage more fully in their backpacking journeys, the lead author followed the backpackers across both physical and virtual spaces. The fieldwork thus covers not only the multiple destinations to which Chinese backpackers travelled in Europe, but also multiple virtual locations, such as travel discussion forums, blogs and social networking sites. While multi-sited ethnography involves 'shadowing' Chinese backpackers through participant observation and interviews at particular places and moments (Bærenholdt, Haldrup, Larsen \& Urry, 2004), netnography is designed to gain a reflexive understanding of online phenomena of culture and communication beyond physical spaces (Hine, 2000; Kozinets, 2015) by participating in and observing backpackers' online activities. Netnography was not only conducted in the stages of pre-trip planning/group formation and post-trip experience sharing, but also during the trip, reflecting the increasing trend for using ICT and social networking sites while 'on the move'. 
Both the interview schedule and the participant observation action plan were developed by focusing on understanding group harmony and group dynamics, and adopted an open approach to generate emerging themes. The backpacking journey was conceived in the research design as comprising three stages: pre-, during and post-trip (Table 1). In Table 1, the research locale represents the destination or virtual space in which the data collection took place, with the research techniques conducted in the three stages accordingly.

Table 1 Research Design

\begin{tabular}{|l||l|l|l|}
\hline \multicolumn{2}{|l||l|l|}{ Pre-trip } & During the trip & Post-trip \\
\hline Netnography & Participant Observation & Participant Observation & Participant Observation \\
\hline Research technique & Qyer.com, WeChat & $\begin{array}{l}\text { WeChat (Group chat \& } \\
\text { WeChat Moment) }\end{array}$ & Qyer.com, WeChat \\
\hline Research Locale & & \\
\hline \hline Multi-sited ethnography & $\begin{array}{l}\text { Semi-structured } \\
\text { interviews, } \\
\text { Participant Observation }\end{array}$ & \\
\hline Research technique & $\begin{array}{l}\text { Spain, Portugal, UK, } \\
\text { Poland }\end{array}$ & \\
\hline Research Locale & & \\
\hline Reflexivity & & \\
\hline
\end{tabular}

Adapting the work of Kozinets (2015) and Tribe and Mkono (2017), we adopted a series of steps for conducting netnography in the research design and data collection. In the initial review stage, Qyer.com was chosen as the online site, and potential informants were contacted. Qyer.com is a leading Chinese outbound travel site founded by a group of Chinese backpackers in Germany in 2004. The literal meaning of Qyer in Chinese is 'poor (budget) travel', which is the philosophy of this online community. As one of the most popular travel websites for outbound backpackers, Qyer.com was initially designed for outbound backpackers in Europe, but now covers destinations all over the world. During the 'pre-trip' stage, informants were contacted and recruited from Qyer.com (Qiongyou Wang) based on Chinese backpackers' motivations (Chen et al., 2014) and characteristics (Lim, 2009; Zhu, 2005). An interactive entrée strategy was followed, in which the lead author actively engaged in pre-trip group forming discussions to explore different group dynamics. The lead author joined three trips, comprising groups of different ages, genders, backgrounds, group sizes, travel experiences and durations of the trips (Table 2). After informants were contacted, the lead author began to collect data such as online posts seeking travel companions, as well as posts about pre-trip planning on WeChat and Qyer.com from informants. 
In the 'during the trip' stage (Table 2), the lead author travelled with the three Chinese backpacker groups in the dual role of backpacker and researcher, and collected data both corporeally and virtually by adopting multi-sited ethnography and continuing netnography while 'on the move'. During the multi-sited ethnography, data were collected in the form of field notes, photographs and informal conversational interviews in relation to group dynamics. In this stage, netnography followed an indexing data collection strategy and focused on the chat history from informants' group chats and social media posts concerning their backpacking experiences from WeChat, China's most used communication service. In addition to following the three Chinese backpacker groups, the lead author conducted semi-structured interviews with backpackers during the trip. The 'post-trip' stage focused on the informants' post-trip activities, with netnography further deployed to explore informants' sharing of experiences online through Qyer.com and WeChat and analyse their travel posts and blogs.

The lead author ensured that the backpackers who participated in the study and the gatekeepers of the travel forum were fully informed, providing participant information and obtaining informants' consent. While consent was implied when observation was undertaken in public areas, the lead author fully disclosed his presence when conducting participant observation in private areas and online forums, where registration was required.

We highly valued the role of co-constructive knowledge in the research process by openly engaging in the collective experience with informants (Jones, 1993); thus, the researcher was not only immersed with the informants, but was also a researched backpacker who co-created sociality and travel experiences with the other backpackers. Identifying himself as a Chinese backpacker, the lead author acted as an 'insider ethnographer' (O'Reilly, 2008) in this study.

Table 2 Details of trips and informant profiles

\begin{tabular}{|c|c|c|c|c|c|c|c|c|}
\hline \multirow{2}{*}{ Trip } & \multirow{2}{*}{ Destination } & \multirow{2}{*}{ Duration } & \multicolumn{3}{|c|}{ Key informants ${ }^{1}$} & \multicolumn{3}{|c|}{ Other Participants ${ }^{2}$} \\
\hline & & & Pseudonym & Age & Gender & Pseudonym & Age & Gender \\
\hline \multirow{4}{*}{1} & \multirow{4}{*}{ Spain + Portugal } & \multirow{4}{*}{34 Days } & Roy & 28 & $\bar{M}$ & Winnie & 24 & $\bar{F}$ \\
\hline & & & David & 25 & M & Lee & 35 & M \\
\hline & & & Sue & 24 & $\mathrm{~F}$ & Rose & 21 & $\mathrm{~F}$ \\
\hline & & & & & & Sammy & 34 & $\mathrm{M}$ \\
\hline 2 & $\overline{\mathrm{UK}}$ & 16 Days & Kady & 42 & $\bar{F}$ & - & & \\
\hline
\end{tabular}




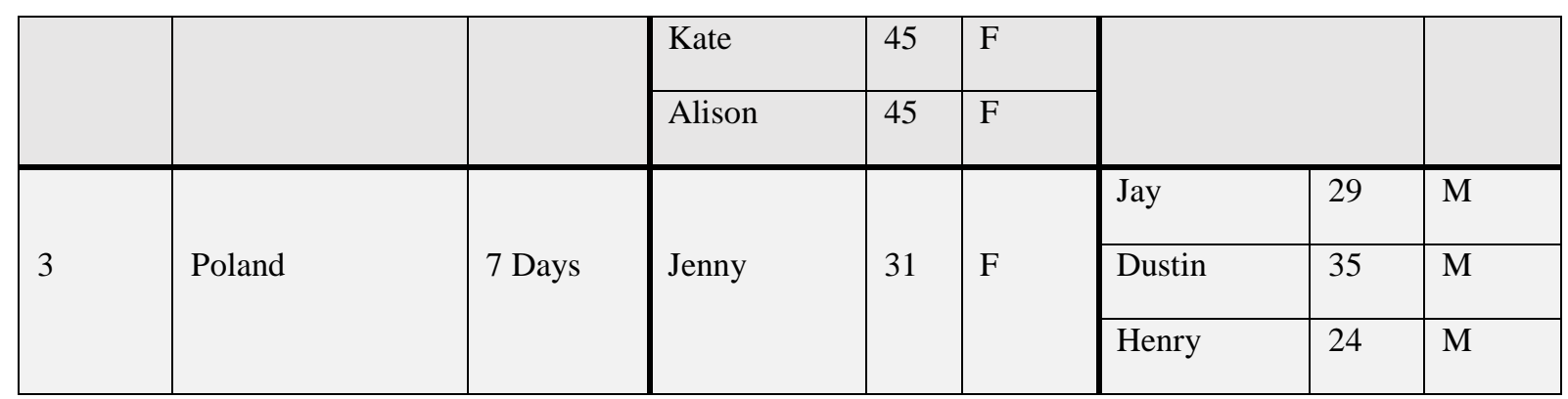

Note: 1: key informants are those Chinese backpackers the lead author recruited from Qyer.com and followed throughout the trip.

2: other participants are Chinese backpackers the lead author met during the trip.

A reflexive methodology requires the researcher to engage both the 'human self' and the 'research self' throughout the research process. To ensure the reflexivity of this research, the lead researcher's values and behaviours during the data collection and writings were continuously, intentionally and systematically reflected on and introspected (Berg, 2004; Feighery, 2006). The lead author took his background as an experienced Chinese backpacker into account, as with other researched backpackers, and tried to balance the role of himself as a backpacker and himself as a researcher during the process to achieve conscious and deliberate inclusion (Sandelowski, 1994). As an insider, the lead author travelled as a backpacker with his informants for three trips and co-created the backpacker experience with the informants.

The lead author kept reflexive notes throughout the fieldwork to note down his feelings in his dual role of researcher and backpacker. This dual role during the study provided a rich interpretation of backpackers' experiences by being one of the donkey friends, and co-creating travel experiences alongside them. These reflexive notes are used as part of the data to understand the group dynamics among Chinese backpackers.

For the multi-sited ethnography, field notes and reflexive notes were collated in diaries over the three trips. Furthermore, 21 semi-structured interviews were conducted during the trip, each lasting an average length of 45 minutes. Online data were collected through screenshots of social media posts and online conversations, as well as digital copies from informants' online travel journals. In total, 570 pages of transcripts from field notes, interviews, reflexive notes, online posts, online chats and travel journals were collected as raw data.

All transcripts were subjected to thematic analysis. Trustworthiness (Decrop, 2004; Lincoln \& Guba, 1985) and rich rigour (Tracy, 2010), as key criteria, were taken into account to ensure the quality of the process of data analysis and writing up. Discord and genuine harmony, as well as the four cultural attributes identified from the literature, guided the data analysis process. In the first cycle, we applied provisional coding (Saldaña, 2015), which begins with a 'start list' 
of codes generated from the literature review. In this study, the start list comprised: group dynamics, surface harmony, genuine harmony and the four Chinese cultural attributes. Pattern coding was used in the second cycle: after grouping the codes into clusters and exploring the relationships between them, three main themes emerged.

The first theme is power relations among donkey friends, which focuses on how the cultural attributes of respect for authority and keqi create different levels of hierarchical but harmonious relations that shape the power dynamics between the head donkey and other donkey friends. The second theme, conflict-free and compromise - the practice of guanxi and conformity in group harmony, examines the cultural attributes of conformity and guanxi with regard to how Chinese backpackers use these skills to deal with discord in order to achieve group goals and retain group harmony. The third theme, how deep is the interaction, concerns the surface harmony and genuine harmony that Chinese backpackers generate as an outcome of their group dynamics, as well as how Chinese backpackers deal with discord in a harmonious manner.

\section{FINDINGS}

\subsection{Power relations among donkey friends}

In the Chinese backpacker community, the role of head donkey is essential to make crucial decisions and take responsibility for the group's harmony (Luo et al., 2015). When asked why she voluntarily took on the large responsibility of head donkey, Jenny said:

'I enjoy very much designing and controlling the itinerary. This is my way: I decide, you follow. I don't like to accommodate others' plans. Donkey friends who respond to my post and who are willing to be my travel companions should agree to my itinerary in the first place' (interview, Poland).

The head donkey has a greater say in various matters; however, this privilege subsequently comes with duties and responsibilities. Kady said: 'I am the person who is assembling this group, so I think I need to take the task of coordination to balance everyone's needs' (interview, UK). The head donkey, therefore, takes charge of maintaining the harmonious status of the group, and ensuring that everyone's needs are met. As the group's head donkey, Kady described herself acting as a commander: 
'At the beginning, I was a bit worried about if you guys will feel I am too intimidating if I keep asking you to do this and that. But things turned out quite smoothly. Normally you guys proactively come to ask me what to do instead, so we plan the details together, it is much easier to do in this way' (interview, UK).

Following the decision of who is the head donkey, power relations are established with roles and tasks then assigned out naturally within the group. For the head donkey, respect and support from fellow donkey friends are the foundation of sustaining harmonious relations. As a fellow donkey friend, Alison talked about her opinions towards the head donkey: 'The head donkey takes all the responsibilities and does all the work of coordination and planning, most of the time I just follow the decision and try not to raise any extra issues' (interview, UK). At the same time as authorising the power to the head donkey, donkey friends also perform their obedient roles as followers by showing no objections to the donkey head's decisions. Correspondingly, the head donkey has the power in most matters but also takes on substantial responsibilities.

Where there is power, usually there is also subversion. Although fellow donkey friends tend to be subservient to maintain the harmonious relationship, there still exists some attempts to negotiate and go against the head donkey's authority. This subversion leads to discord in the group dynamics, however, this is often concealed by surface harmony. One of the most common conflicts is in the trip planning. The following field note excerpt shows how disagreements may occur in trip planning and how 'conflict-free' harmony is used as a tool to cover the discord:

In Valentia, head donkey Roy suggested having a meeting to discuss plans for Andalucía. Sue expressed strong interests in seaside destinations in southern Spain, even though she did not plan much; whilst as the head donkey and the driver, Roy had more concerns about the feasibility and practical issues. During the meeting, they had some fierce arguments, but eventually, as the head donkey, Roy successfully persuaded Sue with a written plan (Figure 1). Neither of them confronted this issue anymore during the trip, but spoke quite negatively about each other in the one-to-one interview. (Participant observation, Spain \& Portugal) 


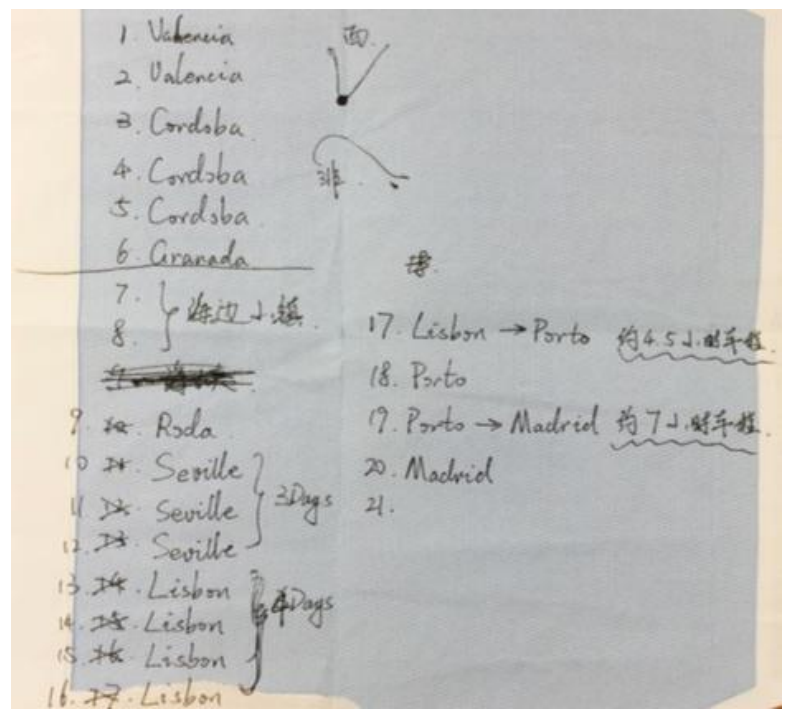

Figure 1 Head Donkey’s Itinerary Planning, Valencia

In this example, group harmony was disrupted by fellow backpackers challenging the head donkey's authority. Although the conflict ended with the head donkey regaining power, the subversion initiated by the donkey friend confused the balance and particular order of social roles in group harmony (Crang, 2015). Discords, therefore, were intensified overtly when the group dynamic lost its harmonious balance, whilst turning to a covert state when the group dynamic was eventually smoothed over by surface harmony.

In this hierarchical social group, head donkeys are inherently assigned with power and authority, but mutually, they are also required to take on considerable responsibilities. These responsibilities paradoxically to some extent limit the head donkey's flexibilities as backpackers: 'at some point during the journey, I really felt like changing the plan and cancelling some bookings. But I need to think about others' feelings too, particularly those who were also part of the planning and booking, not just myself' (Kady, interview, UK). Having a flexible itinerary is one essential characteristic that identifies backpackers (Sørensen, 2003). This flexibility, however, is constrained when taking the role as head donkey: 'when I travelled alone, I rarely planned, but since I am the head donkey I should take responsibility and have a clue where are we going next' (Kady, interview). At the end of the trip, Kady said frankly: 'It is my first-time backpacking in this way, and I don't think it really suits me. This trip confirms that I am the type of person more into solo travel'. The head donkey generally suppresses more personal interests to retain harmonious group dynamics. This suppression of flexibility to some extent leads to negative outcomes of travel experiences. 
In addition to suppressing personal preferences, Roy as the head donkey from the Spain and Portugal trip also experienced some challenges. As the leader, Roy undertook extensive preparatory work during the planning stage. Trying to be liberal and democratic, he also sought opinions when booking accommodations and planning itineraries. However, the travel group seemed not quite active to provide suggestions and ideas (participant observation, Spain \& Portugal). This challenge for Roy firstly can be attributed to 'keqi', referring to 'wellmannered politeness' (Yao, 1983), which is an embodied practice of harmony in Chinese communication to keep a courteous distance with an acquaintance. In the initial stage of communication, although the head donkey holds the power, s/he still practices keqi to create a harmonious communication climate (Xiao, 2004). Secondly, a challenge for the head donkey emerges when fellow backpackers also practice keqi, by respecting the head donkey's opinions so as to avoid unnecessary conflicts. In Chinese backpackers' group dynamics, harmony was created here by practicing keqi in the initial communication, as well as respecting authority in a social group. Nevertheless, to sustain harmonious communication by practicing keqi can be rather confusing and lead to a negative result. Roy was overwhelmed by indifferent responses and 'you decide' answers. He said frankly: 'I feel very stressed that everyone places their expectations on me...Personally, I would be quite upset if any group member is not happy with any decision I made' (interview, Spain \& Portugal). As an indecisive leader, Roy is overwhelmed by his workload; however, to maintain the group harmony, he never confronted this issue with his fellow backpackers (participant observation).

To summarise, group relations between the head donkey and fellow backpackers were developed around power distance. Respect for authority and keqi, cultural attributes highly connected to group harmony, were actively applied by both head donkeys and fellow backpackers to maintain a harmonious and hierarchical group dynamic. The group dynamics were sustained through the advocacy of the power relations. When the balance of power was challenged by subversions of fellow donkey friends, surface harmony was applied to cover the discord to retain the harmonious group dynamic. The group harmony of Chinese backpackers, therefore, is built upon the appreciation of power relations.

\subsection{Conflict-free and compromise}

Kady valued the role of guanxi in the practice of conflict control: 'In my age, my life experience tells me it is very common to have conflicts with others. But the way I deal with it is not to 
intensify it - we cannot get anywhere from it' (interview, UK). Kady's solution practices the old Chinese saying: 'If you are patient in one moment of anger, you will escape a hundred days of sorrow' (忍一时风平浪静, 退一步海阔天空). Wei and Li (2013) believe taking this harmonious strategy is a way to move discord toward genuine harmony. In this case, by treasuring guanxi, donkey friends face and solve the issue that causes the disagreements, and may move from acquaintance to close friends. This practice of guanxi fosters the development of genuine harmony in group dynamics.

However, some informants had a different approach to interpret this guanxi maintenance. Instead of resolving the issue, they tended to hide their strong disagreements, but maintain a 'conflict-free' surface. A consequence of this is that few conflicts could be directly observed during the data collection. However, in one-to-one interviews, informants revealed the discord that lurked underneath the surface harmony. As a backpacker himself, the lead author also hid a few disagreements and disappointing moments:

As a Chinese, I tended to control my feelings in order to avoid confrontation. Instead, I noted down my feelings as a researcher. These feelings are mostly minor disappointments about changing plans, visiting places I was not expecting, perceiving things differently, and disagreeing with others' ideas. I wondered how many subtle moments like this happened to my informants during the trip, but I was unable to observe as they were hiding real emotions to avoid confrontations (Reflexive notes, UK).

Guanxi, in this case, was interpreted by some donkey friends as a tool of surface harmony (Huang, 1999) to cover discordance. Although not optimal, this solution is still preferable in Chinese communications to avoid confrontation (Leung \& Wu, 1998).

Learning to compromise was a big lesson for Kady who was a first-timer travelling with donkey friends recruited online: 'this is the most distinct difference between travelling alone and in a group. It is something new to me. I am interested to see how far I can go' (interview, UK). Undeniably, travelling in a group normally means following a fixed itinerary, and individualistic thoughts are sometimes 'sacrificed' to accomplish the conformity of the group (Thornton et al., 1997). Conformity is both a key characteristic of group travel and a Chinese cultural value. In Chinese culture, practicing mutual compromise to achieve conformity, particularly in a group, is the key to preserving surface harmony (Wei \& Li, 2013). In this case, 
compromises are commonly reached by Chinese group backpackers to ensure the trip is smooth and steady.

To maintain harmonious conformity, fellow donkey friends tended to show no objections to most propositions suggested by the head donkey. Lee (35) explained: 'Chinese people normally are more cautious about others' thoughts, particularly to people they do not know that well. If one person has a proposition, although the idea could be not that great, I will still follow, as others are all doing this. I should cooperate with the majority instead of showing my objection' (interview, Spain \& Portugal). In addition, Jay (29) pointed out that: 'Chinese people tend to hide their emotions and do not tell what they really feel' (interview, Poland). To some extent, this practice of conformity might help to maintain the group harmony, but on the other hand, this surface harmony is achieved through suppressing personal interests, which might lead to dissatisfied experiences or discordant group dynamics.

Although personal interests cannot be met, Chinese backpackers are more likely to take the obedient role to follow. This behaviour can be attributed to the influencing role of conformity. In Chinese society, showing distinctive opinions are discouraged. For Chinese backpackers, to compromise and follow seems much easier than to propose and suggest. As a follower, Alison appreciated decisions the head donkey made; she purposely prepared less to avoid conflicts: ' $I$ knew if I prepare more, I might have stronger opinions or even objections, I'd rather just leave things to Kady, she seems happy to make all the arrangement, I just need to follow. It is better to work this way' (interview, UK). In this case, it is not difficult to understand why Chinese backpackers often say 'whatever' and 'I am fine' in the decision-making process. Consequently, being a leader in a travel group is a challenging role: the head donkey must appreciate other backpackers' compromises, balance each other's interests, as well as taking care that the decision will not upset any fellow donkey friends. Overall, any dramatic emotions caused by disagreements, dissatisfactions and compromises are well covered by the practice of surface harmony, which ensures harmonious guanxi and conformity are sustained, but also fosters potential discords in the group dynamics.

The exploration of discord in this study enriches the understanding of social group harmony. Discord should no longer be considered as the opposite of harmony when understanding travel group dynamics. Instead, discord functions as an essential element of group harmony, which is covered by surface harmony or dealt with through genuine harmony. Discords in group 
dynamics thus facilitate the development of various levels of harmony. It is worth noting that although surface harmony has the potential to develop into genuine harmony as addressed in the literature (Huang, 1999; Leung et al., 2002), surface harmony is mostly utilised to cover potential discord (Leung \& Wu, 1998), instead of developing into a genuine state.

\subsection{How deep is the interaction?}

David (Spain \& Portugal) mentioned one key reason why Chinese backpackers prefer to travel in a culturally homogenous group is that similar cultural backgrounds and common topics between donkey friends may potentially develop deeper levels of interactions. Informants in this study had high expectations to move from acquaintances to friends (Wei \& $\mathrm{Li}, 2013$ ) to achieve a state of genuine harmony, which contributes to positive travel experiences. According to Chen and Chen (2004), Chinese people are good at building up the 'we feeling' of intragroup connections, whilst being indifferent to issues outside the group.

However, despite the optimistic expectations of deeper interactions, in the UK trip, older Chinese backpackers tended to deal with this relationship in a relatively rational way. 'A hedge between keeps friendship green' (君子之交淡如水) is an old Chinese saying used by Kady to describe the relationship among donkey friends. Kate (45) from the same group used 'partially reserved' to label our group communications. She explained: 'we work as a team in this group, every individual is very good at coordinating with each other. However, when it comes to communication, I realise we try to avoid certain topics, such as private issues, jobs, and personal life. However, when others touch those topics, I am very willing to share' (interview, UK). It is therefore relatively difficult to achieve a deep level of group dynamics among donkey friends. As Chang (2001) argues, Chinese interpersonal interactions, particularly with acquaintances, are social performances on a relatively superficial level. Without strong anticipation of developing lifetime friendships, and only as companions for the journey, it is rather difficult to develop genuine harmony from this surface harmony in the backpacking context.

Even though the UK travel group seemed to have the best group dynamics among the three journeys, deep interactions still were not achieved. Nevertheless, it is promising to see that, when the journey approached the end, donkey friends in this group had the tendency to move from acquaintances to close friends: in the last few days, everyone seems to drop the defence 
and open to each other as what close friends do. We talk about any topics and make fun of each other without too many concerns (reflexive note, UK). Genuine harmony thus developed by the end of this trip. One year after the fieldwork, Kady and Alison have teamed up again to backpack in Iran and Morocco. However, most informants held the idea that donkey friends are temporary friends only for this journey, although they were in principle open to further friendship, most of them stopped those relationships when the trip finished. Informants in the group, particularly those who find it difficult to have emotional connections, tend to regard the travel group as a team, and the task is to finish the journey as planned.

In worse scenarios, donkey friends who found themselves with discordant group dynamics tended to avoid conversations and contact during the trip to sustain surface harmony. These discords are attributed to different preferences, strong disagreements in trip planning, and other conflicts of interest. Donkey friends avoid direct conflicts to sustain harmonious ambience in the group. According to Wei and Li (2013), confrontations that lead to the breakdown of harmonious relationships are risky moves. Minimising interactions in a discordant group is the way Chinese backpackers attempt to maintain surface harmony. In the Spain and Portugal group, several awkward moments of silence were experienced:

After getting the Wi-Fi code, everyone was so quiet and focused on his or her mobile phone. At this moment, I felt myself very distant from them, they are so close to me physically, but virtually busily chatting and laughing with friends and relatives far away. I could even feel how noisy and chatty they were in their virtual world compared to this awkward silence (Reflexive notes, Spain \& Portugal).

During the trip, when Chinese backpackers found difficulties in the group, they turned to their familiar social network, mediated by ICT. In this case, 'dining with mobile phones' becomes common practice for a discordant group to retain surface harmony. For the Spain and Portugal trip, Roy found it a relief to have a mobile phone to reduce the awkwardness in the group: 'there is no need to force ourselves to chat if we do not have many common topics. It is just like a reunion with primary school classmates, I do not know what to chat, so we sometimes just play with our phones instead' (interview, Spain \& Portugal). In the second part of this journey, the group maintained the silence for most of the time: some members concentrated on their laptop, some watched Mandarin TV shows, some actively followed what was happening in China, some busily uploaded photos onto social media to show how happy they were. None made 
efforts to communicate. Sue explained: 'I do not think I will meet them for the rest of my life, so it is pointless to make an effort' (interview, Spain \& Portugal). This finding supports observations that the ease of connection with the virtual world enables backpackers to escape from their real-life scenarios (Bull, 2015; Hannam, Butler, \& Paris, 2014). In this case, ICT performs a significant role in that it distracts Chinese backpackers from their intense group relations, and retains the harmonious surface.

Group dynamics have a significant influence on overall travel experiences. Across the three journeys, various levels of group dynamics were achieved based on different interpretations of harmony. None of the groups achieved the deep social interactions they initially expected, though some donkey friends showed the potential of developing genuine harmony. Others used surface harmony either as a tool to facilitate the smoothness of the trip or a cover to prevent direct confrontations. This largely superficial interaction, in opposition to their expectations, though sustaining the harmonious surface, did not assist in creating positive travel experiences.

\section{CONCLUSION}

This study examined how the notion of harmony may allow for new understandings of Chinese backpackers' group dynamics. The findings show that the Chinese cultural attributes of guanxi, keqi, conformity and respect for authority each play a role in negotiating group dynamics to achieve a range of harmonious statuses. Power relations were initially formed when the travellers were looking for travel companions online. When backpacking together in 'real' life, this hierarchical relationship between strangers was carefully maintained by practicing respect for authority and keqi, which are accepted as common codes for both the head donkey and donkey friends. However, our findings suggest that the over-practice of keqi leads to confusion and potential discord in the groups. In addition to keqi, guanxi is another key cultural attribute that donkey friends follow to maintain harmonious group dynamics. Our research found that donkey friends in different states of group dynamics interpret guanxi differently, resulting in either genuine or surface harmony. To achieve conformity of the group, personal opinions are suppressed to align with the group interest. This might result in a harmonious surface, but the discord underneath is not resolved. Most Chinese backpackers perform surface harmony to cover discord or retain the power relations; few of them adopt a sincere approach in developing 
genuine relations. The findings from the perspective of group dynamics provide new understandings of Chinese outbound backpackers' travel experiences.

This paper contributes to knowledge by first revealing the group dynamics among selforganised groups, and their relationship with the overall travel experience, whereas most previous studies have tended to focus on group dynamics within the context of package tours (Quiroga, 1990; Tucker, 2005; Yarnal \& Kerstetter, 2005). Second, it frames and positions the essential role of harmony in Chinese travel group dynamics. Third, it provides a new interpretation of harmony in the tourism context by synthesising various levels of group harmony with the four Chinese traditional attributes of respect for authority, guanxi, keqi and conformity.

This paper also contributes to the backpacker literature. Based on the group orientations of Chinese backpackers (Luo et al., 2015; Miao \& Bao, 2007), this study explores the actual experiences of these self-organised backpacker groups. The findings also add to the backpacker literature from a cross-cultural perspective, focusing on group dynamics rather than the individual experiences considered in previous studies (Loker-Murphy \& Pearce, 1995; Sørensen, 2003). Chinese outbound backpackers arrange the group in advance through the Internet, providing a new understanding of the current development of backpacker studies. From forming travel groups online and the use of mobile technology to maintain surface harmony, the findings not only reflect and contribute to understanding of the increasingly important and multifaceted role of ICT in backpacking (Paris, 2012), they also differ from previous research focusing on impromptu social interaction from the individual backpacker's perspective by showing the impact of a fixed group on the backpackers' experiences, which contributes to understanding of a diversified backpacker segment.

This study has several practical implications. Firstly, given the popular phenomenon among Chinese backpackers of looking for travel companions online, resulting in mere surface harmony within group dynamics, online backpacker forums should improve travel companion search features in order to facilitate Chinese backpackers finding like-minded people with whom to travel. Secondly, this research also provides opportunities for mobile application developers, especially Location Based Services. Applications can be designed to help Chinese backpackers, and others, to find travel companions during the trip, which may provide them with more flexibility and options in forming travel groups. 
We recognise some limitations of this study. First, in this case, social harmony, although providing a deeper understanding of travel group dynamics, was only approached from a Chinese perspective. Group dynamics play a significant role in travel experiences and with the increasing popularity of self-organised group travel, further studies of self-organised group dynamics in other cultural settings are needed. Second, this study discussed the various roles of four key Chinese cultural attributes in developing surface and genuine group harmony; however, although harmony is one of the fundamental philosophies in Chinese culture, there are other interrelated cultural attributes that should be considered such as 'face', humility and emotional self-control. Future studies may explore these interconnections, which will further enrich understanding of the importance of group harmony in tourism.

\section{REFERENCES}

Adkins, B. A., \& Grant, E. L. (2007). Backpackers as a community of strangers: The interaction order of an online backpacker notice board. Qualitative Sociology Review, 3(2).

Bærenholdt, J. O., Haldrup, M., Larsen, J., \& Urry, J. (2004). Performing tourist places: Ashgate Publishing Ltd.

Baron, R., \& Kerr, N. (2003). Group Process, Group Decision, Group Action 2/E: McGrawHill Education (UK).

Benur, A. M., \& Bramwell, B. (2015). Tourism product development and product diversification in destinations. Tourism Management, 50, 213-224.

Berg, B. L. (2004). Qualitative research methods for the social sciences (Vol. 5): Pearson Boston.

Bull, M. (2015). Sound moves: iPod culture and urban experience: Routledge.

Chang, H. C. (2001). Harmony as performance: The turbulence under Chinese interpersonal communication. Discourse studies, 3(2), 155-179.

Chen, G. M. (2013). The two faces of Chinese communication. The global intercultural communication reader, 27-36.

Chen, G., Bao, J., \& Huang, S. S. (2014). Segmenting Chinese backpackers by travel motivations. International Journal of Tourism Research, 16(4), 355-367.

Chen, G., Huang, S., \& Hu, X. (2018). Backpacker Personal Development, Generalized SelfEfficacy, and Self-Esteem: Testing a Structural Model. Journal of Travel Research, doi.org/10.1177/0047287518768457.

Chen, G., \& Huang, S. S. (2017). Toward a theory of backpacker personal development: Crosscultural validation of the BPD scale. Tourism Management, 59, 630-639.

Chen, X. P., \& Chen, C. C. (2004). On the intricacies of the Chinese guanxi: A process model of guanxi development. Asia Pacific Journal of Management, 21(3), 305-324.

Cohen, E. (1972). Toward a Sociology of International Tourism. Social Research, 39(1), 164182.

Cohen, E., \& Cohen, S. A. (2015). Beyond Eurocentrism in tourism: A paradigm shift to mobilities. Tourism Recreation Research, 40(2), 157-168.

Crang, M. (2015). Travelling ethics: Valuing harmony, habitat and heritage while consuming people and places. Geoforum, 67, 194-203. 
Crompton, J. L. (1981). Dimensions of the social group role in pleasure vacations. Annals of Tourism Research, 8(4), 550-568.

Decrop, A. (2004). Trustworthiness in qualitative tourism research. Qualitative research in tourism: Ontologies, epistemologies and methodologies, 156-169.

du Cros, H., \& Jingya, L. (2013). Chinese Youth Tourists Views on Local Culture. Tourism Planning \& Development, 10(2), 187-204.

Falzon, M.-A. (2016). Multi-sited ethnography: Theory, praxis and locality in contemporary research: Routledge.

Feighery, W. (2006). Reflexivity and tourism research: Telling an (other) story. Current Issues in Tourism, 9(3), 269.

Feng, H., \& Chen, G. (2004). Keqi and Chinese communication behaviors. Theories and principles of Chinese communication, 435-450.

Fong, V. L. (2004). Only hope: Coming of age under China's one-child policy: Stanford University Press.

Gilbert, M. (1992). On social facts: Princeton University Press.

Hannam, K., Butler, G., \& Paris, C. M. (2014). Developments and key issues in tourism mobilities. Annals of Tourism Research, 44, 171-185.

Hine, C. (2000). Virtual ethnography: Sage.

Hofstede, G. (1980). Culture's consequences: International differences in work-related values (Vol. 5): Sage Publications, Incorporated.

Hsu, C. H., \& Huang, S. S. (2016). Reconfiguring Chinese cultural values and their tourism implications. Tourism Management, 54, 230-242.

Huang, L. (1999). Interpersonal harmony and conflict: Indigenous theories and research. Taipei: Gui Guan.

ITB. (2018). ITB World Travel Trend Report 2017/18: Boom or Bust? Where is Tourism Heading.

Jin, X., \& Wang, Y. (2016). Chinese Outbound Tourism Research A Review. Journal of Travel Research, 55(4), 440-453.

Jones, P. (1993). Studying society: sociological theories and research practices: HarperCollins.

Kozinets, R. V. (2015). Netnography: Redefined. London: Sage.

Kwek, A., \& Lee, Y.-S. (2010). Chinese tourists and Confucianism. Asia Pacific Journal of Tourism Research, 15(2), 129-141.

Kwek, A., \& Lee, Y.-S. (2015). How "Face" Matters: Chinese Corporate Tourists in Australia. Journal of Travel \& Tourism Marketing, 32(1-2), 120-140.

Leung, K., Koch, P. T., \& Lu, L. (2002). A dualistic model of harmony and its implications for conflict management in Asia. Asia Pacific Journal of Management, 19(2-3), 201-220.

Leung, K., \& Wu, P. G. (1998). Harmony as a Double-Edge Sword in Management. In B. S. Cheng, K. L. Huang \& C. C. Kuo (Eds.), Human Resources Management in Taiwan and China. Taiwan: Yuan Liou Publishing.

Lim, F. K. G. L. (2009). 'Donkey Friends' in China: The Internet, Civil Society, and the Emergence of the Chinese Backpacking Community. In T. Winter, P. Teo \& T. C. Chang (Eds.), Asia on Tour: Exploring the Rise of Asian Tourism (pp. 291-301). Oxon: Routledge.

Lincoln, Y. S., \& Guba, E. G. (1985). Naturalistic inquiry (Vol. 75). London: Sage.

Loker-Murphy, L., \& Pearce, P. L.(1995). Young budget travelers: Backpackers in Australia. Annals of Tourism Research, 22(4), 819-843.

Long, Y. (2011). Backpacking tourism culture in network times: Taking Cang Qiong Outdoor Tourism Club as an example. Tourism Tribune, 26, 71-77.

Luo, X., Huang, S., \& Brown, G. (2015). Backpacking in China: A netnographic analysis of donkey friends' travel behaviour. Journal of China Tourism Research, 11(1), 67-84. 
Marcus, G. E. (1995). Ethnography in/of the World System: The Emergence of Multi-Sited Ethnography. Annual Review of Anthropology, 24, 95-117.

McIntosh, A. J., \& Zahra, A. (2007). A cultural encounter through volunteer tourism: Towards the ideals of sustainable tourism? Journal of sustainable tourism, 15(5), 541-556.

Miao, X., \& Bao, J. (2007). Grounded theory of non-standardized groups travel. Tourism Tribune, 22(8), 44-54.

Moise, E. E. (1995). Modern China: a History. UK: Longman.

Mok, C., \& DeFranco, A. L. (2000). Chinese cultural values: Their implications for travel and tourism marketing. Journal of Travel \& Tourism Marketing, 8(2), 99-114.

Money, R. B., \& Crotts, J. C. (2003). The effect of uncertainty avoidance on information search, planning, and purchases of international travel vacations. Tourism Management, 24(2), 191-202.

Murphy, L. (2001). Exploring social interactions of backpackers. Annals of Tourism Research, 28(1), 50-67.

Nash, R., Thyne, M., \& Davies, S. (2006). An investigation into customer satisfaction levels in the budget accommodation sector in Scotland: A case study of backpacker tourists and the Scottish Youth Hostels Association. Tourism Management, 27(3), 525-532.

O'Reilly, K. (2008). Key concepts in ethnography: Sage Publications Limited.

Ong, C. E., \& du Cros, H. (2012). The post-Mao gazes: Chinese backpackers in Macau. Annals of Tourism Research, 39(2), 735-754.

Paris, C. M., \& Teye, V. (2010). Backpacker motivations: A travel career approach. Journal of Hospitality Marketing \& Management, 19(3), 244-259.

Paris, C. M. (2012). FLASHPACKERS: An Emerging Sub-Culture? Annals of Tourism Research, 39(2), 1094-1115.

Pearce, P. L., \& Foster, F. (2007). A “university of travel”: Backpacker learning. Tourism management, 28(5), 1285-1298.

Pearce, P. L., Wu, M.-Y., \& Osmond, A. (2013). Puzzles in understanding Chinese tourist behaviour: Towards a triple-C gaze. Tourism Recreation Research, 38(2), 145-157.

Peng, M. (1997). The importance of guanxi (connections) in China. Chow et al.(Eds), Business Strategy, an Asia-Pacific Focus, Prentice-Hall, New York, NY.

Prayag, G., Disegna, M., Cohen, S. A., \& Yan, H. (2015). Segmenting markets by bagged clustering: Young Chinese travelers to Western Europe. Journal of Travel Research, 54(2), 234-250.

Prebensen, N. K., \& Foss, L. (2011). Coping and co- creating in tourist experiences. International Journal of Tourism Research, 13(1), 54-67.

Qian, X. (2001). Harmony: Each in its due place. Journal of Tsinghua University Philosophy and Social Sciences, 5, 3-8.

Quiroga, I. (1990). Characteristics of package tours in Europe. Annals of tourism research, $17(2), 185-207$.

Saldaña, J. (2015). The coding manual for qualitative researchers: Sage.

Sandelowski, M. (1994). Focus on qualitative methods. Notes on transcription. Research in Nursing \& Health, 17(4), 311-314.

Shaffer, T. S. (2004). Performing backpacking: Constructing" authenticity" every step of the way. Text and performance quarterly, 24(2), 139-160.

Song, H., Wang, Y., \& Sparks, B. A. (2018). How do young Chinese friendship groups make travel decisions? A content and interaction process analysis. Journal of Travel \& Tourism Marketing, 1-14.

Sørensen, A. (2003). Backpacker ethnography. Annals of Tourism Research, 30(4), 847-867. 
Thornton, P. R., Williams, A. M., \& Shaw, G. (1997). Revisiting Time-Space Diaries: An Exploratory Case Study of Tourist Behaviour in Cornwall, England. Environment and Planning A: Economy and Space, 29(10), 1847-1867.

Tracy, S. J. (2010). Qualitative quality: Eight "big-tent" criteria for excellent qualitative research. Qualitative inquiry, 16(10), 837-851.

Tribe, J., \& Mkono, M. (2017). Not such smart tourism? The concept of e-lienation. Annals of Tourism Research, 66, 105-115.

Tucker, H. (2005). Narratives of place and self: Differing experiences of package coach tours in New Zealand. Tourist Studies, 5(3), 267-282.

Tuomela, R. (1995). The importance of us: A philosophical study of basic social notions.

Wei, X., \& Li, Q. (2013). The Confucian value of harmony and its influence on Chinese social interaction. Cross-Cultural Communication, 9(1), 60.

Wong, S., \& Lau, E. (2001). Understanding the behavior of Hong Kong Chinese tourists on group tour packages. Journal of travel research, 40(1), 57-67.

Wong, Y., \& Tam, J. L. (2000). Mapping relationships in China: Guanxi dynamic approach. Journal of Business \& Industrial Marketing, 15(1), 57-70.

Wu, M. Y., \& Pearce, P. L. (2014). Chinese recreational vehicle users in Australia: A netnographic study of tourist motivation. Tourism Management, 43, 22-35.

Xiang, Y. (2013). The Characteristics of Independent Chinese Outbound Tourists. Tourism Planning \& Development, 10(2), 134-148.

Xiao, X. (2004). Li and Chinese communication behaviours In G. M. Chen (Ed.), Theories and Principles of Chinese communication, 379-405.

Yang, J., Ryan, C., \& Zhang, L. (2016). Social Conflict and Harmony: Tourism in China's Multi-Ethnic Communities (Vol. 23). Bingley: Emerald Group Publishing Limited.

Yao, W. (1983). The importance of being KEQI: A Note on Communication Difficulties. Communicating with China, 71-75.

Yarnal, C. M., \& Kerstetter, D. (2005). Casting off an exploration of cruise ship space, group tour behavior, and social interaction. Journal of Travel Research, 43(4), 368-379.

Yau, O. H. (1988). Chinese cultural values: Their dimensions and marketing implications. European Journal of marketing, 22(5), 44-57.

$\mathrm{Yu}, \mathrm{X}$., Weiler, B., \& Ham, S. (2002). Intercultural communication and mediation: A framework for analysing the intercultural competence of Chinese tour guides. Journal of Vacation Marketing, 8(1), 75-87.

Zhang, J., Morrison, A. M., Tucker, H., \& Wu, B. (2018). Am I a Backpacker? Factors Indicating the Social Identity of Chinese Backpackers. Journal of Travel Research, 57(4), 525-539.

Zhang, J., Tucker, H., Morrison, A. M., \& Wu, B. (2017). Becoming a backpacker in China: A grounded theory approach to identity construction of backpackers. Annals of Tourism Research, 64, 114-125.

Zhang, W., \& Watts, S. (2008). Online communities as communities of practice: a case study. Journal of Knowledge Management, 12(4), 55-71.

Zhu, X. (2005). A Probe into the Characteristics of Backpackers and Their Influences on the Development of Chinese Tourist Destinations [J]. Tourism Science, 3, 007.

Zhu, X. (2009). Theoretical and Empirical Study on Backpacker Tourism: China Travel and Tourism Press. 